\title{
C/N RATIO OF MULBERRY LEAVES FED TO SILKWORM, Bombyx mori L. LARVAE AS AN INDEX FOR ITS PRODUCTIVITY. \\ Eid, M. A. A. ${ }^{1}$; Souad M. Mahmoud'; S. A. S. El-Maasarawy'; Hanan M. A. Hamada' and Ghada M. A. Hammad² 1- Faculty of Agric., Cairo Univers. Econom. Entom. Depart. \\ 2- Seric. Res. Dept., Plant Prot. Inst., Agric. Res. Cent.
}

\begin{abstract}
The present study was conducted to evaluate the performance of five mulberry varieties used for rearing the bivoltine race (EJ) of mulberry silkworm. Nutritional composition of the leaves was determined. Carbohydrate/protein $(\mathrm{C} / \mathrm{N})$ ratios were focused. Also, leaf/cocoon ratios and its suitability for judging the mulberry leaves efficiency were determined.

The results show significant differences between varieties. Kokuso-27 and Kearyang-Seoban-3 show higher nutritional components followed by Josaengrok-2. While the lowest value were recorded in Morittiana and Kokuso-20 varieties. Kokuso27 and Kearyang-Seoban-3 recorded lowest values in $\mathrm{C} / \mathrm{N}$ ratio and in leaf/cocoon ratio, and therefore, Kokuso-27 and Kearyang-Seoban-3 give more superiority over other varieties, they can be used as criteria for comparing the different mulberry varieties.

The biological and economic characters of silkworm were reflection of higher values of leaf nutritional contents, lower values of carbohydrate/ protein ratio and leaf /cocoon ratio.
\end{abstract}

\section{INTRODUCTION}

The quality of mulberry leaves as food for silkworm larvae plays an important role in the nutritional aspects and silk quality affects the economy of sericulture industry (Mahmood et al., 1987 and Qader et al., 1995). The feeding efficiency of silkworm depends on the leaf palatability (Reddy and Swamy, 1999; Patil et al., 2001 and Susheelamma et al., 2007). The larvae of silkworm, Bombyx mori L. feed almost exclusively on mulberry leaves, where they digest and absorb more than $60 \%$ of the nitrogenous components of the leaves. The $5^{\text {th }}$ instar larvae utilize around $65 \%$ of the ingested nitrogenous substances to produce silk threads (Horie and Inokuchi, 1978 and Shree and Mahadeva, 2005). The principal components of mulberry leaves are water and dry matter which is consisted of protein, carbohydrates, fats, inorganic salts and vitamins (Chuan and Chuang, 1988). All of these elements are essential nutrients for the physiological functions of the silkworms. The nutritional value of the leaves varies greatly according to different factors such as variety of mulberry leaves, position and maturity of leaves, fertilization, photoperiod and season. Mulberry leaves are considered as good sources of starch, protein, and carotene in healthy leaves (Singhal et al., 1999 and Tang et al., 2005 and 2006). Bongale and Chaluvachari (1995); Reddy et al. (2003) and Garcia et al. (2005) reported that mulberry leaves varieties exhibited significant differences with respect to soluble protein, total 
sugar and chlorophyll contents. The larval weight and molting ratios of silkworms were associated with higher values of leaf moisture content, moisture retention and lower values of sugar/protein ratio (Chaluvachari and Bongale, 1995 and Mala et al., 2000).

This study aims to determine the nutritional composition of leaves of five mulberry varieties and their effect on larval growth and silk production. The $\mathrm{C} / \mathrm{N}$ ratio and leaf/cocoon ratio were used as criteria to determine the efficiency of different mulberry varieties.

\section{MATERIALS AND METHODS}

Mulberry trees: Five mulberry varieties; one variety introduced from Japan (Morus japonica var. Kokuso-20 (Ko-20)), two varieties introduced from South Korea (Morus ihou Koidz. var. Josaengrok-2 (Jo-2) and Morus alba Linn. var. Kearyang-Seoban-3 $(K e-3))$ and two varieties from The Sericulture Research Station (Morus alba Linn. var. Kokuso-27 (Ko-27) and Morus alba Linn. var. Morittiana (Mo)) were used in this study.

The mulberry varieties were raised at the same block design at a space of $2 \times 2 \mathrm{~m}$. and paired row system $(2+2 \mathrm{~m}$.) spacing and package of practices recommended by The Sericulture Research Department.

The experiment was conducted for two full growing season covering one entire physiological period i.e. from one pruning to another. Plantation was ten years old at the time of evaluation under the same natural conditions. The plants were pruned to the height of $(1.50 \mathrm{~m}$.) above the ground. Cultural practices were followed as recommended by Hosny and Mahmoud (2002).

Test insects: Silkworm Bombyx mori L. eggs were obtained from The Sericulture Research Department of Plant Protection Research Institute, Ministry of Agriculture and land reclamation in Giza. Rearing was carried out during two successive seasons of 2006 and 2007 using the selected silkworm, $(E J)$ race and the different mulberry varieties. Five treatments were carried out, 300 larvae for each. Leaves of the five mulberry varieties were harvested and separately fed to the larvae during the whole feeding period of the larval stage. An equal amount of leaves was given to each batch four meals per day. Rearing of silkworm and experimental techniques were carried out under laboratory conditions $\left(28^{\circ} \mathrm{C} \pm 2\right.$ and $\left.80 \mathrm{RH} \%\right)$. Regular cleaning of rearing beds was carried out to avoid disease infection.

Criteria used for evaluation.

1. Mulberry.

a. Leaf moisture: Leaves were harvested during spring (during feeding the $5^{\text {th }}$ instar larval).

The moisture content of leaf was calculated according to Patil et al., 2001 and expressed in terms of percentage.

b. Chemical components of mulberry leaves: Fresh leaves of the five mulberry varieties were collected to determine chlorophyll $a, b$, total chlorophyll and carotene according to Holden (1965), total lipids according to the procedure of the AOAC (2000) and total amino acids according to Etsushiro et al. (1981).

Another sample of leaves was dried in a hot air oven at $70{ }^{\circ} \mathrm{C}$, till constant weight and kept for determining the nitrogen, crude protein, and true 
protein according to AOAC (1995), total carbohydrate and hydrolysable carbohydrate according to Dubois et al. (1956).

c.The $\mathbf{C} / \mathrm{N}$ ratio: $\mathrm{C} / \mathrm{N}$ ratio were calculated by relating the carbohydrate/protein $(\mathrm{C} / \mathrm{N})$ ratio represented by the nitrogen content of protein and its suitability for judging the mulberry leaves efficient as an index for their productivity during spring rearing season.

2. Biological performance of silkworm.

a. Larval duration: Total larval duration (in days) were observed from day of hatching till day of spinning and recorded in days for each treatment.

b. Growth rate: The growth rates measured as the gain in weight over the initial weight at the $4^{\text {th }}$ and $5^{\text {th }}$ instars were calculated according to the Waldbauer (1968).

Growth rate $=$

Weight gained during the period / [Duration of the period (days) $x$ Mean of insect weight].

c. Weight of larvae: Thirty larvae of $4^{\text {th }}$ and $5^{\text {th }}$ instar from each treatment were weighed separately then average weight was calculated.

d. Hatchability: Before hatching, 10 egg cards from each treatment were counted, before and after hatching, then hatchability was estimated as following equation of Lea (1996):

Hatchability $(\%)=\mathrm{H} / \mathrm{F}$ X 100

Where, $\mathrm{H}$ : Number of hatched larvae. $\quad \mathrm{F}$ : Number of fertilized eggs.

3. Economic parameters.

a. Weight of cocoons: Cocoon from each treatment was carefully opened and pupae were first sexed, then thirty cocoons of each sex were weighed separately and average weight was calculated.

b. Weight of cocoon shell: The previously weighed cocoons were cleaned from exuviae and the average weight was per the cocoon shell calculated.

c. Cocoon shell ratio \%: Cocoon shell ratio was calculated for both sexes in each treatment according to Tanaka (1964) as follows:

Cocoon shell ratio $(\%)=[$ Cocoon shell weight $/$ Fresh cocoon weight $] \times 100$ d. Number of cocoons per liter: The amount of cocoons produced from each treatment were determined by number of cocoons per liter (number/size).

4. Leaf / Cocoon ratio: During each instar, mulberry leaves were weighed every day in the beginning of feeding, and then placed in a plastic sack covered with wetted piece of cotton in front of each replicate. The weighed leaves were offered to silkworm larvae 4 times daily, (i.e. at 9 a.m., 1, 4 and 9 p.m). At the end of each instar, the remaining food was weighed, young larvae ( $1^{\text {st }} 3^{\text {rd }}$ instars) were fed on weighed chipped leaves, whereas the grown ones $\left(4^{\text {th }}\right.$ and $5^{\text {th }}$ instars) were fed on weighed whole leaves. The mature larvae were transferred to a mounting fork.

The cocoons were harvested 7 days later, then the cocoon crop was weighed and food consumed per 1000 larvae and fresh cocoon yield per 1000 larvae were weighed to estimate leaf / cocoon ratio as the quantity of mulberry leaves consumed by the larvae to produce one kilogram of fresh cocoons. 


\section{RESULTS}

1. Chemical components of different mulberry leave varieties: The chemical constituents of mulberry leaves play a major role in the production of silk. Fig.(1, 2, 3, 4 and 5) show the mean values of various components and the relationship between carbohydrate and protein concentrations in mulberry leaves of different varieties.

a. Leaf moisture: Fig. (1) show that the moisture content which is considered one of the most important evaluating factors between the mulberry varieties.

The highest percentages were found in Ke-3 (74.41\%) and Ko-27 (71.02\%) and the lowest in Mo (65.64\%).

b. Pigment content: Among the mulberry varieties studied, it was found that Ko-27, Ke-3 and Jo-2 show higher chlorophyll (a) content (2.30, 2.27 and $2.11 \mathrm{mg} / \mathrm{gfwt}$.), respectively. While, the $\mathrm{Mo}$ and $\mathrm{Ko}-20$ varieties show less chlorophyll (a) content (1.66 and $1.12 \mathrm{mg} / \mathrm{gfwt}$.), respectively (Fig. 2). The chlorophyll (b) content was higher in Ko-27 (1.52 mg/gfwt.) and Ke-3 (1.37 $\mathrm{mg} / \mathrm{gfwt}$.) and the lowest contents were recorded in Mo and Ko-20 (0.99 and $0.89 \mathrm{mg} / \mathrm{gfwt}$.), respectively (Fig. 2). The total content of chlorophyll was much higher in Ko-27 (3.82 mg/gfwt.) followed by Ke-3 (3.64 mg/gfwt.). In case of carotenoid pigments the highest value was recorded in Ko-27 (1.49 $\mathrm{mg} / \mathrm{gfwt}$.) followed by $\mathrm{Ke}-3$ (1.32 mg/gfwt.) (Fig. 2).

c. Total lipids, Amino acids and protein contents: Contents of total lipids are shown in Fig. (3). The highest concentration of total lipid content was observed in $\mathrm{Ko}-27$ and $\mathrm{Ke}-3$ varieties (8.99 and $8.30 \mathrm{mg} / \mathrm{gfwt}$.). respectively, while in Jo-2, Mo and Ko-20 lower values were obtained.

Show slight variation in total amino acid content of the five mulberry varieties. The highest level of free level of free amino acids in all the mulberry varieties was found in Ko-27 (20.0\%) while the lowest was in Ko-20 (12.5 $\%)$.

The percentage of protein content presented in Fig. (3) show that there are great variation in crude protein. The percentage of crude protein was $29.75 \%$ in $\mathrm{Ko}-27$ but in $\mathrm{Ko}-20$ was $22.31 \%$. While $\mathrm{Ke}-3$, Jo-2 and Mo varieties recorded $(28.26,26.78$ and $23.80 \%)$, respectively. The true protein recorded $(24.99,23.74,22.50,19.99$ and 18.74\%) in Ko-27, Ke-3, Jo-2, Mo and $\mathrm{Ko}-20$ varieties. respectively (Fig. 3).

d. Total nitrogen and total carbohydrate contents: Nitrogen as one of the major plant nutrients plays an important role in yield and quality of mulberry.

The nitrogen content of the five mulberry varieties were determined and show in Fig. (4). Slight variation was observed in nitrogen content of the different mulberry varieties leaves.

Fig. (4) revealed differences in carbohydrate content between the five mulberry varieties. A conspicuously high value was observed in Ko-27 (23.56\%) when compared to Mo and Ko-20 (19.49 and 18.31\%), respectively. The mean level of hydrolysable carbohydrate was highest in Ko-27 compared to $\mathrm{Ko}-20$. 
e. The $\mathbf{C} / \mathbf{N}$ ratio: An understanding of the nature of association of the carbon with the nitrogen contents would give appropriate suggestions in the judgment and selection procedures for mulberry varieties. Therefore, the $(\mathrm{C} / \mathrm{N})$ ratio for the five mulberry varieties under study were calculated and illustrated in Fig. (5). The ratios of total carbohydrate to nitrogen content in the leaves registered $(4.950,4.969,5.019,5.117$ and 5.129) in Ko-27, Ke-3, Jo-2, Mo and Ko-20 varieties, respectively.

2. Biological performance of silkworm.

a. Larval duration: Larval duration from hatching eggs till spinning the cocoons was estimated as an important parameter because increased larval duration have an influence on rearing performance, cocoon and grainage parameters. The obtained results in Fig. (6) show that the five mulberry varieties had no effect on larval duration of the young instars, while during the $4^{\text {th }}$ larval instar, the mulberry variety Ko-27 recorded the shortest duration (7.0 day).

During the $5^{\text {th }}$ instar, Ko-20 recorded the longest duration (9.5 day). The total larval duration was $36.0,36.5,36.5,36.5$ and 37.0 days with Ko-27, $\mathrm{Ke}-3, \mathrm{Jo}-2, \mathrm{Mo}$ and Ko-20, respectively Fig. (6).

b. Growth rate: Values of growth rate as a relation between the weight at the end of the instar to the weight at the end of the previous instar of the $4^{\text {th }}$ and $5^{\text {th }}$ instars were estimated.

The values of growth rate were $0.103,0.097,0.098,0.097$ and 0.102 and $0.088,0.084,0.085,0.087$ and 0.077 of the $4^{\text {th }}$ and $5^{\text {th }}$ instars larvae fed on Ko-27, Ke-3, Jo-2, Mo and Ko-20, respectively Fig. (7). The weight gain in $4^{\text {th }}$ instar larvae was highest in larvae fed on Ko-27 (0.103) and Ko-20 (0.102)

During the $5^{\text {th }}$ instar, the highest weight gain was in larvae fed on Ko27 followed by $\mathrm{Ke}-3$, then $\mathrm{Jo}-2, \mathrm{Mo}$ and $\mathrm{Ko}-20$. It could be concluded that Ko27 improved the growth rate value compared to the other four mulberry varieties.

c. Weight of larvae: Weight of grown larvae ( $4^{\text {th }}$ and $5^{\text {th }}$ instars) fed on different mulberry varieties differ significantly.

The mean weight of $4^{\text {th }}$ instar larvae fed on Ko-27, Ke-3, Jo-2, Mo and $K o-20$ were $0.698,0.707,0.678,0.537$ and $0.535 \mathrm{gm}$., respectively (Fig. 8).

While weights of $5^{\text {th }}$ instar larvae fed on the same mulberry varieties recorded (3.513, 3.074, 2.919, 2.347 and 1.955gm.), respectively (Fig. 8).

d. Hatchability percentage: The obtained results of the mean values of egg hatchability are show in Fig. (9). Slight variation with no significance between the mulberry varieties was observed. The estimated percentage recorded $(95.48,95.40,93.01,92.04$ and $91.50 \%)$ after feeding the silkworm larvae on Ko-27, Ke-3, Jo-2, Mo and Ko-20, respectively.

\section{Economic parameters:}

a. Cocoon weight: The female and male cocoon weights were found to be significantly higher with $\mathrm{Ko}-27, \mathrm{Ke}-3, \mathrm{Jo}-2, \mathrm{Mo}$ and $\mathrm{Ko}-20$.

The female cocoon weights were 1.562, 1.435, 1.314, 1.287 and $1.097 \mathrm{gm}$. of larvae fed on Ko-27, Ke-3, Jo-2, Mo and Ko-20, respectively Fig. 
Eid, M. A. A. et al.

(10). While the male cocoon weights recorded for the same varieties were 1.268, 1.181, 1.079, 1.004 and $0.931 \mathrm{gm}$., respectively Fig. (10).

b. Cocoon shell weight: The highest cocoon shell weight was obtained when mulberry variety $\mathrm{Ko}-27$ was fed to larvae followed by Ke-3, Jo-2, Mo and $K o-20$.

Female cocoon shell weights recorded $(0.295,0.262,0.241,0.239$ and $0.201 \mathrm{gm}$.) and male cocoon shell weights were $(0.278,0.244,0.230$, 0.222 and $0.184 \mathrm{gm}$.) for $\mathrm{Ko}-27, \mathrm{Ke}-3, \mathrm{Jo}-2, \mathrm{Mo}$ and $\mathrm{Ko}-20$, respectively Fig. (10).

c. Cocoon shell ratio: Cocoon shell ratios followed the same trend of cocoon weight and cocoon shell weight. The highest cocoon shell ratio for both female and male were obtained from larvae fed on $\mathrm{Ko}-27$ then $\mathrm{Ke}-3$, Jo2 and $\mathrm{Mo}$, while Ko-20 recorded the least values. The female cocoon ratios were $18.886,18.257,18.340,18.570$ and $18.380 \%$, while male cocoon ratios were $21.924,20.660,21.316,22.111$ and $21.138 \%$, respectively (Fig. 11).

Significant differences were obtained between the male cocoon shell ratios with the different varieties. The overall performance of the three parameters showed their highest values in Ko-27, followed by Ke-3 and Jo-2, whereas $M o$ and $K o-20$ showed the least values.

d. Number of cocoons per liter: The number of cocoons / liter which is used as criterion for cocoon classification in Egypt was determined and shown in (Fig. 12). The least number was recorded for cocoons resulted from larvae fed on Ko-27 (108.7 cocoon) followed by Ke-3 (113.7 cocoon) and Jo-2 (115.0 cocoon) then Mo (143.0 cocoon) and Ko-20 (143.7 cocoon) with significant differences between the mulberry varieties. It was found that the higher protein content in both $K o-27$ and $K e-3$ is utilized for protein biosynthesis leading to a significant increase in shell weight.

4. Leaf/Cocoon ratio: Leaf/cocoon ratio is an important character related to the economic cocoon production as it is the quantity of mulberry leaves consumed by the larvae to produce one kilogram of fresh cocoon. Fig. (13) show the leaves consumed and fresh cocoon yield per 1000 silkworm larvae and the leaf / cocoon ratio.

The total consumed leaves by larvae fed on Ko-27, Ke-3, Jo-2, Mo and Ko-20 varieties weighed $(19.34,18.55,18.07,17.40$ and $16.31 \mathrm{Kg}$.), respectively. While the cocoon yield for the abovementioned varieties were $(1.27,1.14,1.02,0.95$ and $0.87 \mathrm{Kg}$.), respectively.

The estimated leaf/cocoon ratios were 15.24, 16.28, 17.69, 18.23 and 18.78, respectively Fig. (13).

From the obtained results it is advocated that Ko-27 followed by Ke-3 are preferable for silkworm rearing under the climatic conditions in Egypt. There were significant differences in cocoon production, cocoon shell weight and percentage of cocoon shell ratio. Assuming that the percent cocoon shell ratio is the quotient of shell weight over cocoon weight, the high values obtained may be due to the substantial weight of the cocoon shell, which is a desired effect.

Tayade and Jawale (1984) reported that by feeding different silkworm strains on a varied genetic materials, obtained a higher cocoon yield with the mulberries selected, but did not note any difference in the silk ratio. 
Also, Satyanarayana et al. (1990); Sarkar and Fujita (1994); Mahmoud (2000) and Sujathamma et al. (2001) confirmed the superiority of a mulberry variety over another in terms of cocoon, cocoon shell weight and cocoon shell ratio. Basaiah (1988); Sannappa and Jayaramaiah (1999) and Patil et al. (2000) reported similar observation in Philosamia ricini silkworm, they found that the type of host / variety fed to the silkworms determined the cocoon traits.

The present study also revealed that the best leaf / cocoon ratio was found when larvae were fed on Ko-27 (15.24), compared to the highest ratios found in $\mathrm{Mo}$ and $\mathrm{Ko}-20$ (18.23 and 18.78). Similar observations were reported by Basaiah (1988); Sannappa et al. (2000) and Jayaranaiah and Sannappa (2002) in Samia Cynthia ricini silkworm. They observed that leaf / cocoon ratio was influenced by castor leaves genotypes, it was higher in Aruna type while the lowest ratio was found in R-C-8 type. Jayaramajah and Sannappa (2005) reported that leaf / cocoon ratio was higher in Karnataka India (30-35) comparing to the same in Japan (15-18).

The high content of chlorophyll and carotene content as an indication of more photosynthetic pigment production. Further, increasing of leaf moisture and other nutrients like total nitrogen, crude protein in the leaves may serve as one of the criteria for estimating their quality. Enhancement of nutrient value of mulberry leaves having favorable effect on palatability and digestibility of silkworm.

The nutritional components of mulberry leaves (chlorophyll, carotene, lipids, amino acids, proteins and carbohydrate) show negative association with larval duration. On the other hand larval weight increases with increasing values of these parameters. Higher content of these parameters my have an indirect effect to accelerate the growth and development of the late age silkworm larvae and also the cocoon production. $\mathrm{C} / \mathrm{N}$ and leaf/cocoon ratios show negative association with growth and silk yield of larvae.

Based on the obtained results regarding the growth parameters and the chemical constituents and considering the obtained results of $\mathrm{C} / \mathrm{N}$ and leaf/cocoon ratios, it could be suggested that mulberry varieties of less $\mathrm{C} / \mathrm{N}$ ratio and less leaf/cocoon ratio are preferable for selection and could be recommended than varieties with highest $\mathrm{C} / \mathrm{N}$ and leaf/cocoon ratios.

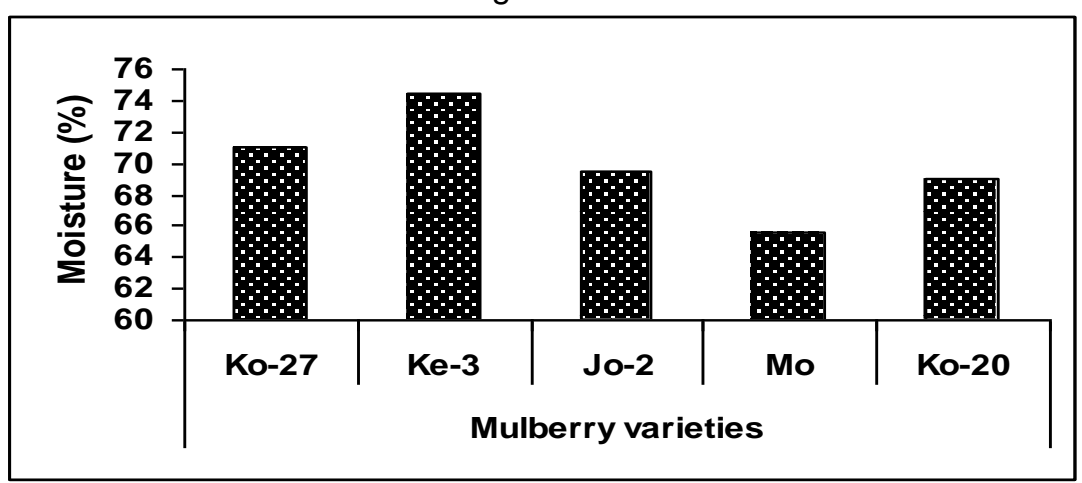

Fig. 1: Moisture content in the leaves of different mulberry varieties. 
Eid, M. A. A. et al.

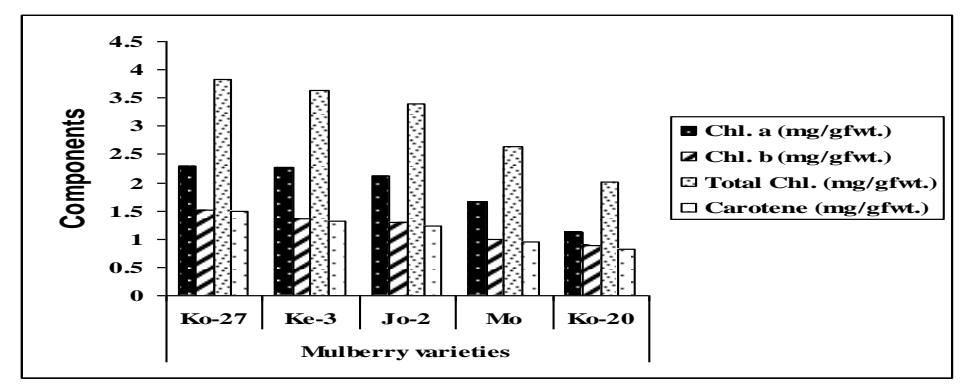

Fig.2: Pigment contents in the leaves of different mulberry varieties.

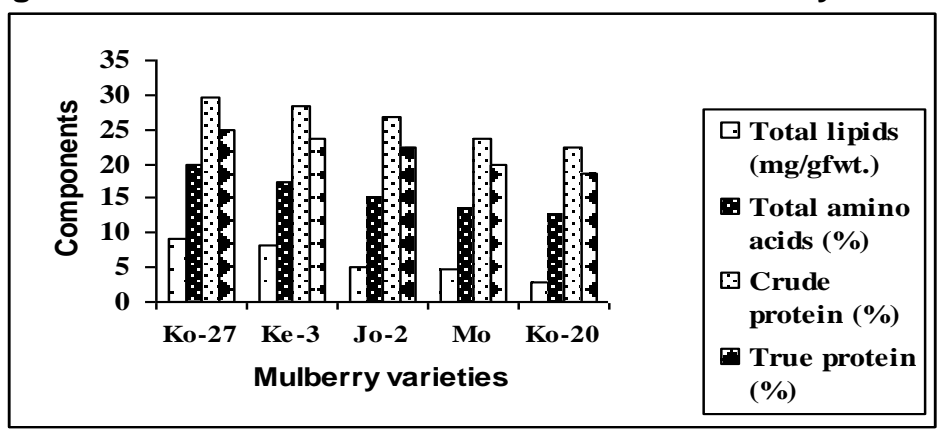

Fig.3: Chemical analyses of various components in the leaves of different mulberry varieties.

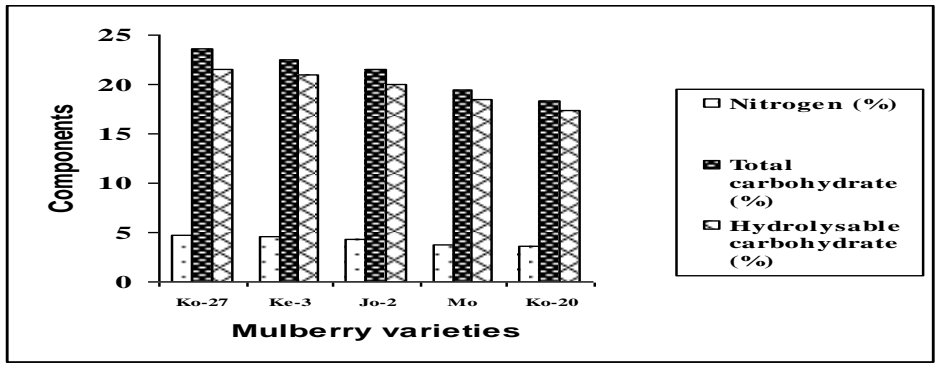

Fig. 4: Percentage of nitrogen, total carbohydrate hydrolysable carbohydrate in the leaves of different mulberry varieties.

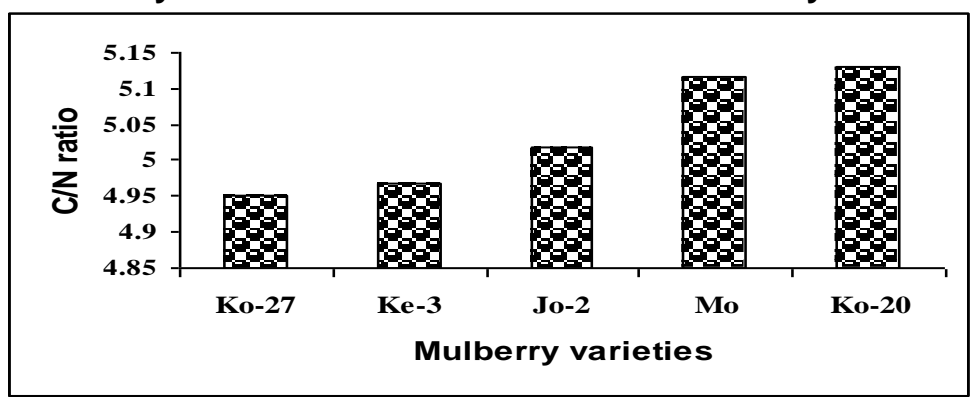

Fig. 5: $\mathrm{C} / \mathrm{N}$ ratios of mulberry leaves fed to silkworm, Bombyx mori $\mathrm{L}$. larvae as an index for its productivity. 


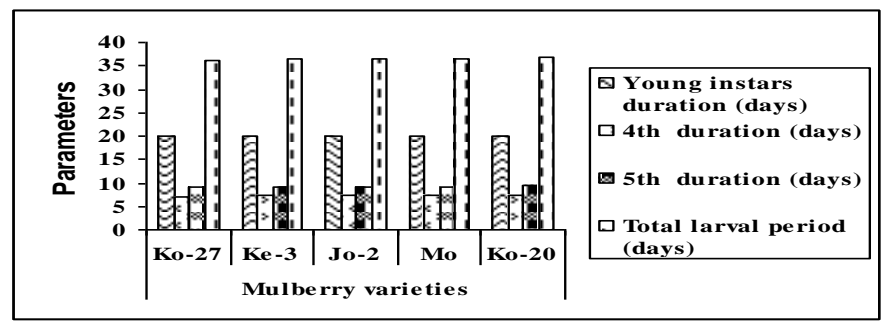

Fig. 6: Effect of feeding with different mulberry leaf varieties on larval duration.

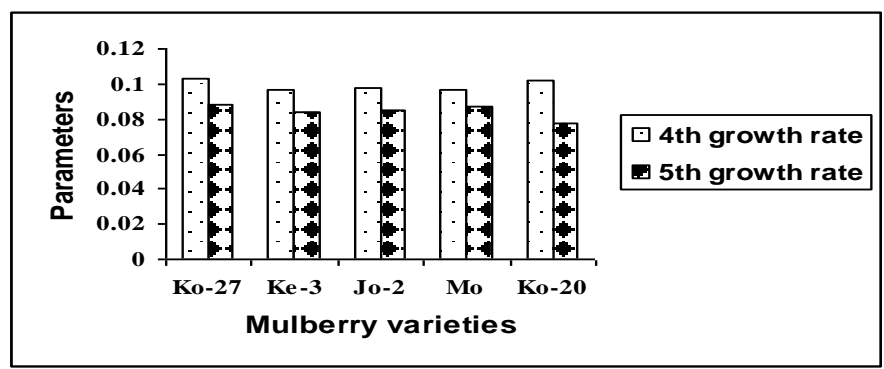

Fig. 7: Effect of feeding with different mulberry leaf varieties on growth rate.

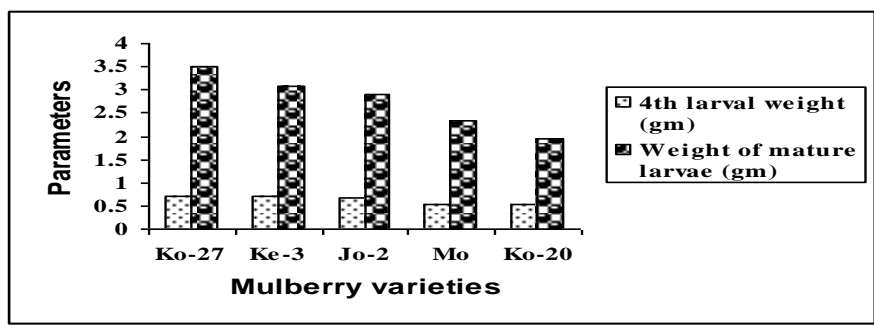

Fig. 8: Effect of feeding with different mulberry leaf varieties on larval weight.

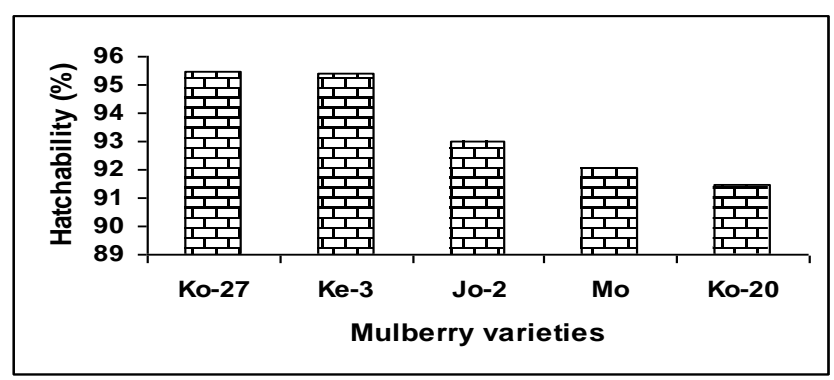

Fig. 9: Effect of feeding with different mulberry leaf varieties on hatchability (\%). 
Eid, M. A. A. et al.

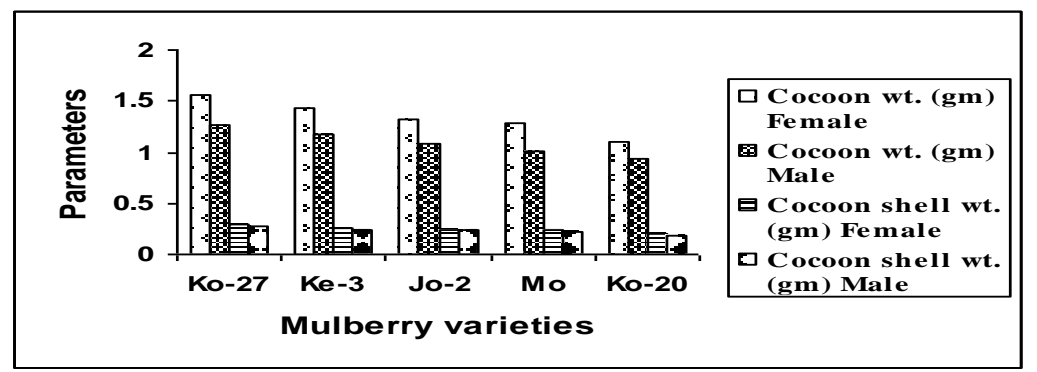

Fig. 10: Effect of feeding with different mulberry leaf varieties on economic characters of silkworm, Bombyx mori L.

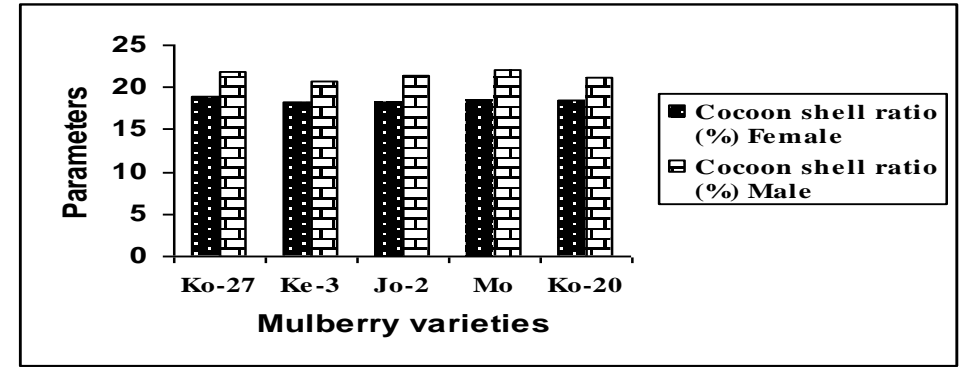

Fig. 11: Effect of feeding of different mulberry varieties on the cocoon shell ratio.

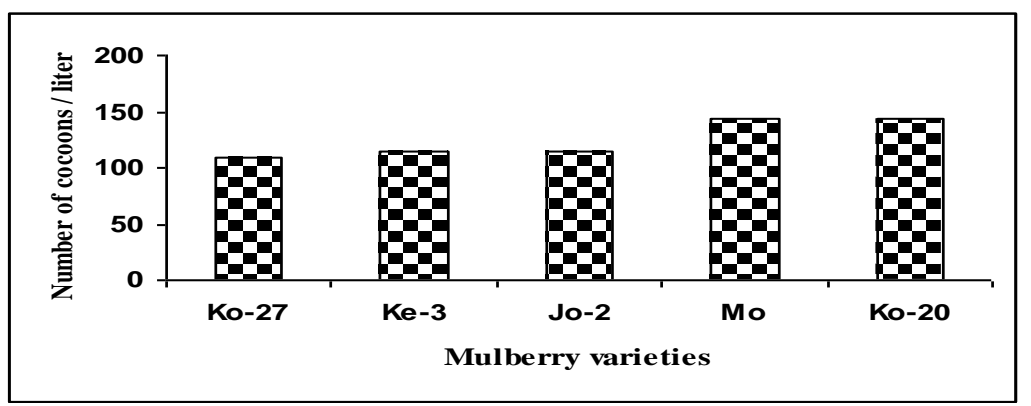

Fig. 12: Effect of feeding of different mulberry varieties on the number of cocoon per liter.

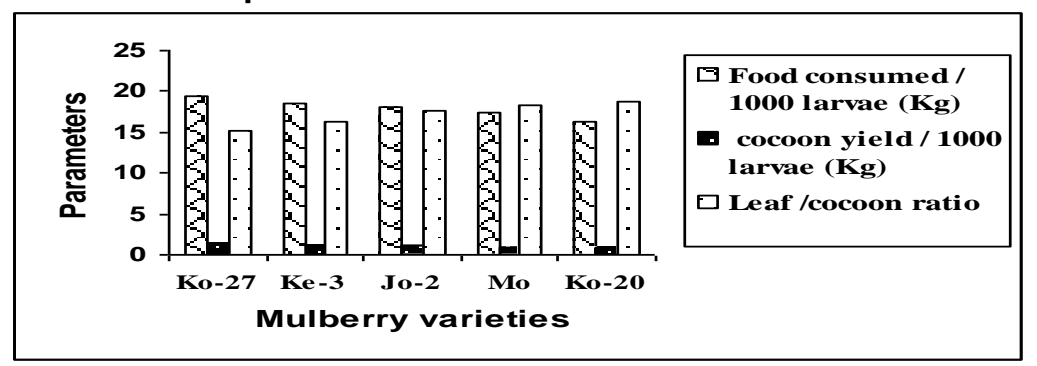

Fig. 13: Effect of feeding of different mulberry varieties on the consumed food, fresh cocoon yield /1000 larvae and leaf / cocoon ratio. 


\section{DISCUSSION}

From the chemical analyses of mulberry leaves of different varieties (Fig. 1, 2, 3, 4 and 5) it is discernable that no single variety all the nutrients are present in the highest level. But from the silkworm nutrition point of view, leaf nutrients as total protein, free amino acids, carbohydrate and total lipids are considered to be very important.

This fact was confirmed by the findings of Jolly and Dandin (1986) who found that $70 \%$ or more moisture content in the mulberry leaves is necessary for optimum silkworm rearing. Satyanarayana et al. (1990) found that moisture content in the mulberry leaves ranged between $67.775-69.844 \%$, while Ahmed (1999) observed that moisture content or cellulose constituents did not differ between Kukuso-27, Kukuso-21, Morittiana and Kanava-2. Rajendiran et al. (1993) recorded that quality of mulberry leaves is determined by its moisture retention capacity. Mala et al. (2000) confirmed that water content of the leaves has direct bearing on growth of silkworm in its different stages.

Fig. (2) revealed that the chlorophyll and carotene pigment contents were higher in Ko-27, Ke-3 and Jo-2 but lower in Mo and Ko-20. The variation in pigment contents between the varieties are in accordance with (Cappelozza et al., 1995 and Eid et al., 2005). They reported that the amount of chlorophyll $\mathrm{a}, \mathrm{b}$, total chlorophyll and carotene ranged between (1.57-2.76, 0.52-1.51, 2.09-4.28 and 1.03-1.45 mg/gfwt.).

According to the obtained results, the superiority of Ko-27 and Ke-3 in photosynthesis is confirmed. Silkworm larvae need certain quantities of lipids for its growth and egg production. This fact is in accordance with Chen (1971), who reported that lipids are important components of cells. The importance of lipids was also clarified by Hamumura et al. (1961), they reported that the lipid soluble factor known as $\beta$-sitostirol, present in the mulberry leaves accelerate larval biting action. Purohit and Kumar (1996) found that lipid contents of dry matter of mulberry leaves ranged from 3 to $6 \%$. Mahmoud (2000) determined the lipid contents of Kokuso-27 and found to be $4.64 \%$. While Wael (2009) found that the total lipids was $(6.20$ $\mathrm{mg} / \mathrm{gdwt}$.) in Kokuso-27.

The importance of amino acid contents in the leaves on silkworm were reported by Ito (1960) as he found that the best larval growth is attained with $20 \%$ amino acids diet and the rate of silk production is better with 25$30 \%$ amino acids. Kirimura (1962) reported that some of the silk amino acids are derived from mulberry leaves and some are synthesized in the body of the larvae. Satyanarayana et al. (1990) found that amino acids content in the mulberry leaves ranged between $32.86-41.20 \mu \mathrm{g} / \mathrm{g}$ dry wt. It was found that the mean levels of crude protein percentage were relatively higher in $\mathrm{Ko}-27$ and $\mathrm{Ke}-3$ and $\mathrm{Jo}-2$. True protein percentages were also estimated and found to be in the same orders of crude protein.

These results are in accordance with (Soohoo and Frankel, 1966; Minko and Miricheva, 1979), who reported that crude protein percentages were 18.70 to $23.20 \%$ in mulberry leaves as against 27.30 to $28.69 \%$ in Morus laevigata and from $26.51-27.68 \%$ in Morus alba variety and assured 
the importance of protein contents of the leaves as they found that nearly $70 \%$ of the silk proteins produced by silkworm are directly derived from the protein of mulberry leaves. Also, Satyanarayana et al. (1990) found that crude protein percentages in the mulberry leaves ranged between 20.10 to $27.97 \%$.

Results of the nitrogen content of the mulberry varieties are in accordance with Sarkar et al. (1997) and Patil et al. (2001). They reported that the total chlorophyll content, total soluble sugars, the soluble proteins and the total nitrogen content in mulberry leaves showed positive association with effective rate of rearing (ERR) by weight, single cocoon weight, shell weight (in protein) and shell ratio (in nitrogen). The mulberry varieties with higher content of nitrogen in leaf show higher production efficiency of cocoon shell weight. The mean level of total and hydrolysable carbohydrate was higher in Ko-27 compared to Ko-20. Similar observations were reported by Mahmoud (2000) who proved that the highest values of soluble sugar were obtained in Kokuso-27 (121.15 mg/dwt.). Wael (2009) also found that the total carbohydrates were $(128.0 \mathrm{mg} / \mathrm{gdwt}$.) in Kokuso-27, while in Kanava-2 were $(72.66 \mathrm{mg} / \mathrm{gdwt}$.).

The $\mathrm{C} / \mathrm{N}$ ratio was decreased with increasing of protein concentrations in mulberry leaves which can be used as criterion for comparison between the different varieties and as an index for their productivity. This ratio recorded 4.950 in Ko-27 and (5.129) in Ko-20 (Fig. 5).

This fact was supported by Li and Sang (1984) who reported that the cocoon crop was high in silkworms fed on mulberry leaves in which the nitrogen / carbon ratio ranged between 3.5 and 5, while the economic characters were low in silkworms fed on mulberry leaves in which the nitrogen / carbon ratio was less than 3. Chaluvachari and Bongale (1995) recorded significant differences among the varieties both in respect of leaf biochemical components and bioassay molting test parameter. They found that the larval weight and molting ratios of silkworms were associated with higher values of leaf moisture content, moisture retention and lower values of sugar/ protein ratio.

The leaves of the five mulberry varieties showed variation with respect to major nutrients such as total free amino acids, total protein and leaf moisture content. When the means of all the five varieties were considered, the leaf moisture and chemical constituents studied were relatively higher in Ko-27 and $\mathrm{Ke}-3$ varieties over $\mathrm{Mo}$ and $\mathrm{Ko}-20$.

In order to confirm the findings of the chemical analyses, feeding trials were also conducted with all the five different varieties of mulberry leaves.

\section{REFERENCES}

Ahmed, A. M. (1999). Improving the silkworm productivity in Assiut area. M.Sc. Thesis, Fac. Agric. Assiut Univ., Egypt., :96.

A.O.A.C. (1995). Method of analysis. Association of Official Agriculture Chemist., $16^{\text {th }}$ ed Washington, D.C. 
A.O.A.C. (2000). Official methods of analysis. Association of Official Analytical Chemist., $14^{\text {th }} \mathrm{cd}$ Washington, D.C.

Basaiah, J. M. M. (1988). Consumption and utilization of castor and tapioca by the eri silkworm, Samia Cynthia ricini Boisd. M.Sc. Thesis, Univ. Agric. Scien., Bangalore,: 119.

Bongale, U. D. and Chaluvachari (1995). Evaluation of eight mulberry germplasm varieties by leaf biochemical and bioassay moulting studies. Sericologia, 35 (1): 83-94.

Cappelozza, L.; Coradazzi and Tornadore, N. (1995). Studies on the phenotypic variability of seven cultivars of Morus alba I. and three of Morus monticules P. (Moraceae) - Part 1. Sericologia, 35 (2): 257-270.

Chaluvachari, G. and Bongale, U. D. (1995). Evaluation of leaf quality of some germplasm genotypes of mulberry through chemical analysis and bioassay with silkworm, Bombyx mori L. Indian J. of Sericulture, 43(2): 127-132.

Chen, P. S. (1971). Biochemical aspects of insect development. S. Krager, Basel, : 55-65.

Chuan, W. P. and Chuang, C. D. (1988). Silkworm rearing. FAO Agricultural Services Bulletin, 73 (2): 12-13.

Dubois, M.; Smith, F.; Gilles, K. A.; Hamilton, J. K. and Rebers, P. A. (1956). Calorimetric method for determination of sugars and related substances. Anal. Chem., 28 (3): 350-356.

Eid, M. A. A.; Mahmoud, M. S.; El-Maasarawy, S. A. S. and Hammad, G. M. A. (2005). Chemical differences of silkworm, Bombyx mori L. products as indes of races. J. Agric. Sci. Mansoura Univ.,30 (5): 2865-2879.

Etsusuhiro, D., Daisuke, S., and Eruyoshi, M. (1981). Modified colorimetric ninhydrin methods for peptidase assay. Anal. Biochem, $118: 173-184$.

Garcia, D. E.; Medina, M. G. and Ojeda, F. (2005). Soluble carbohydrates in four varieties of mulberry (Morus alba Linn.). Pastosy Forrajes., 28: (3) 233-239.

Hamamura, Y.; Hayashiya, K. and Naito, K. (1961). Food selection by silkworm larvae, Bombyx mori L. $\beta$-sitosterol as one the biting factors. Nuture, 190: 880-881.

Holden, (1965). Chlorophylls in chemistry and biochemistry of plant pigmented. Goo. Win. T. W. Academic Press London,: 462-488.

Horie, Y. and Inokuchi, T. (1978). Protein synthesis and uric acid excretion in the absence of essential amino acid in the silkworm, Bombyx mori $\mathrm{L}$. Insect Biochem., 8 : 251-254.

Hosny, A. and Mahmoud M. S. (2002). Cocoon production of Bombyx mori L. raised on leaf crop of two types of mulberry fields around the year. $2^{\text {nd }}$ International Conference. Plant Protection Research Institute, CairoEgypt, 1:222-225.

Ito, T. (1960). Effect of sugars on feeding larvae of the silkworm, Bombyx mori L. J. Insect Physiol., 5: 95-107. 
Jayaranaiah, M. and Sannappa, B. (2002). Influence of castor genotypes on cocoon traits and reproductive potential in eri silkworm, Samia Cynthia ricini Boisd. The $19^{\text {th }}$ Congr. Inter. Seric. Comm. Bangkok, Thailand,: 256-260.

Jayaranaiah, M. and Sannappa, B. (2005). Influence of castor genotypes on cocoon traits and reproductive potential in eri silkworm, Samia Cynthia ricini. The $20^{\text {th }}$ Congr. Inter. Seric. Comm. Bangalor India,: 256-260.

Jolly, M. S. and Dandin, S. B. (1986). Collection, conservation and evaluation of mulberry (Morus ssp.) Germplasm. Central Sericultural Research and Training Institute, Mysore, India,: 44.

Kirimura, A. (1962). Bull. Sericulture Expt. Stn., 17: 447.

Lea, H. Z. (1996). Basic principles and practical techniques of silkworm. Breeding department of biology, Kangown National University, Chunchon, Korea.

$\mathrm{Li}, \quad$ R. and Sang, Q. (1984). The relationship between quality of mulberry leaves and some economic characters during the later larval stage. Science of Sericulture Canye Kexue, 10 (4): 197-201.

Mahmood, K.; Ahmad, M. and Gilani, A. H. (1987). Effect of feeding leaves of Mourus alba and Mourus laevigata on larval growth and silk yield of silkworm, Bombyx mori. Pakistan J. Zool., 19 (3): 239-243.

Mahmoud, M. S. (2000). Feeding effects of five mulberry varieties on the silkworm, Bombyx mori L. Egypt J. App. Sci., 15 (6): 253-261.

Mala, V. R.; Dandin, S. B.; Magdum, S. B. and Datta, K. K. (2000). Nutritional evaluation of mulberry (Morus ssp.) genotypes through silkworm growth studies. Uttar Pradesh J., 20: 47- 53.

Minko, P. and Mircheva, D. (1979). Composition and digestibility of nutrients in leaves of different mulberry varieties in silkworm trial. Zhivoinov, Dnanki, 16: 123-128.

Patil, G. M.; Kulkarni, K. A.; Patil, R. K. and Badiger, K. S. (2000). Performance of eri silkworm Samia Cynthia ricini Boisd on different castor genotypes. Int. J. Wild. Silkmoth \& silk, 5: 193- 195.

Patil, S. V.; Mallikarjunappa, R. S.; Dandin, S. B. and Eswara, R. M. S. (2001). Evaluation of improved genotypes of mulberry through leaf chemical analysis and bioassay with silkworm races NB4D2. Sericologia, 41 (2): 219-226.

Purohit, K. M. and kumar, T. P. (1996). Influence of various agronomical practices in India on the leaf quality in mulberry, a review. Sericologia, 36 (1): 27-39.

Qader, M. A.; Haque, R. and Absar, N. (1995). Nutritive effects of bush, lowcut and tree mulberry leaves of economic characters of silkworm, Bombyx mori L. Pakistan J. of Zoology, 27(1): 77-81.

Rajendiran, P. M.; Himantharaj, M. T.; Meenal, A.; Rajan, R. K.; Kamble, C. K. and Datta, R. K. (1993). Importance of water in sericulture. Indian silk, (8): 46-47.

Reddy, B. K.; Rao, D. M. R.; Reddy, M. P.; Jayaram, R. H. and Suryanarayana, N. (2003). Variation of chlorophyll content and its relationship with leaf area and leaf yield in mulberry genotypes (Morus spp.). Advances in Plant Sciences., 16: (1) 277-280. 
Reddy, D. N. R. and Swamy, K. C. N. (1999). Effect of host on the consumption rate, leaf-cocoon and leaf-egg ratio of Eri silkworm, Samia Cynthia ricini Boisduval. Entomon., 24 (1) 67-70.

Sannappa, B. and Jayaramaiah, M. (1999). Interaction of castor genotypes and breeds of eri silkworm, in relation to cocoon and grain age parameters. Mysore J. of Agric. Sciences, 33(2): 214- 223.

Sannappa, B.; Jayaramaiah, M.; Reedy D. N. R.; Shrikanth, C. and Rangaswamy, S. (2000). Consumption and leaf : cocoon ratio of erisilkworm on castor genotypes. Proc. Natl. Sem. Tropic. Seric. , Eds. K.P. chinnas wamy, R. Govidan, N.K. Krishnaprasad and D.N.R Reddy, USA, Bangalore, 3: 47-49.

Sarkar, A. and Fujita, H. (1994). Better technique for nutritive evaluation of mulberry leaves for silkworm, Bombyx mori. Indian J. of Seric., 33(1): 19-22.

Sarker, A. ; Haque, M. R.; Rab, M. A. and Absar N. (1997): Studies on crude protein and amino acid contents of mulberry (Morus alba I.) leaves in relation to cocoon production of the silkworm, Bombyx mori $\mathrm{L}$. Sericologia, $37: 137-142$.

Satyanarayana, R.; Pallavi, S. N.; Munirathnam, R. M.; Suryanarayana, N.; Signan, B. K. and Sengupta, N. (1990). Evaluation of four new mulberry varieties through silkworm rearing under irrigated condign. Indian J. of Seric., 29(2): 240-247.

Shree, M. P. and Mahadeva, A. (2005). Biochemical studies in the insect pest infested mulberry varieties and their impact on sericulture. Advances in Indian entomology: productivity and health (a silver jubilee supplement No.3, Volume 1). Uttar Pradesh Zoological Society, Muzaffarnagar, India, : 173-186.

Singhal, B. A.; Mala, V. R.; Sarkar, A. and Dataa, R. K. (1999). Nutritional disorders of mulberry (Morus spp.) III. Leaf nutrient guide for secondary nutrients. Sericologia, 39 (4): 599-609.

Soohoo, C. F. and Frankel, G. (1966). The consumption, digestion and utilization of the food plants by polyphegous insect Procenia eridania (Gramer). J. Insect Physiol., 12: 711-730.

Sujathamma, P.; Dandin, S. B. and Savithri, G. (2001). Quality evaluation of mulberry (Morus spp.) genotypes through bioassay under Rayalaseema conditions of Andhra Pradesh. Indian J. of Sericulture, 40 (1): $27-34$

Susheelamma, B. N.; Kesavacharyulu, K.; Urs, M. K. P. R. and Balakrishna, R. (2007). Chlorophyll content as leaf quality determinant trait in mulberry (Morus indica L.). Advances in Plant Sciences., 20 (1): 113115.

Tanaka, Y. (1964). "Sericologia" Central Silk Board, Bombay. B- Meghdoot, Marine Drive 216-220.

Tang, M. A. K.; Salam, K. A.; Samad, M. A. and Absar, N. (2005). Nutritional changes of four varieties of mulberry leaves infected with fungus (Cercospora moricola). Pakistan J. of Biological Sciences, 8 (1): 127131. 


\section{Eid, M. A. A. et al.}

Tang, A. K.; Samad, M. A.; Akand, A. S. M. A. H.; Azhar, B. S. and Absar, N. (2006). Nutritional changes of four varieties of mulberry leaves infected with fungus (Pyllactinia corylea). Pakistan J. of Biological Sciences., 9 (3): 355-359.

Tayade, D. S. and Jawale, M. D. (1984). Studies on the comparative performance of silkworm races against different varieties of mulberry under Marathwada conditions. Sericologia, 24 (3): 361-364.

Wael, F. M. (2009). Nutritional efficiency of certain compounds on silk production and fecundity of mulberry silkworm. M.Sc. Thesis, Fac. Agric. Ain Shams Univ., Egypt.

Waldbauer, C. P. (1968). The consumption and utilization of food by insects. Adv. Insect physical., 5:229-282.

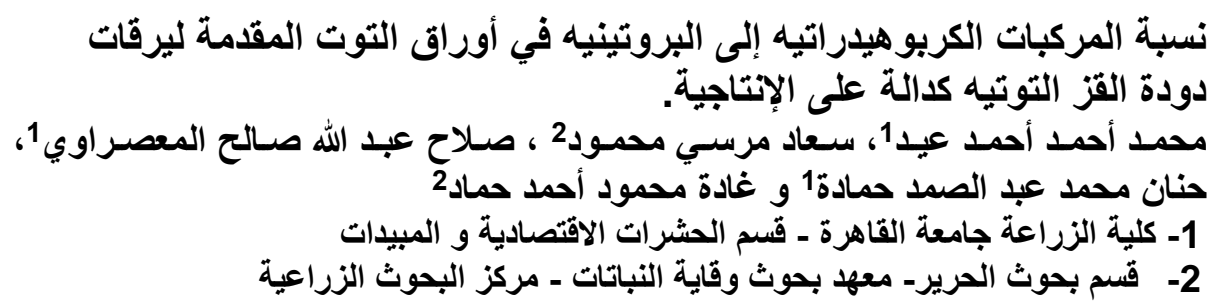

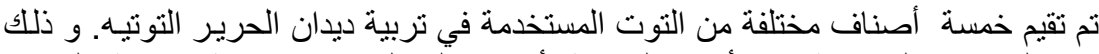

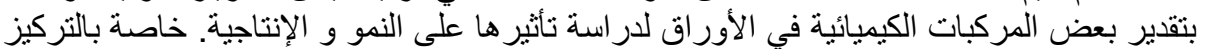

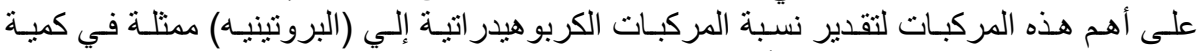

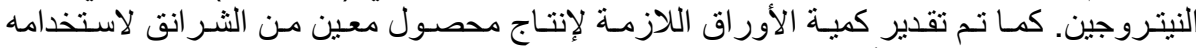

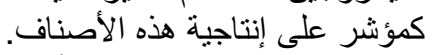

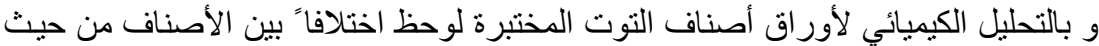

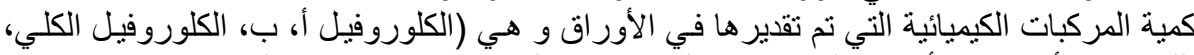

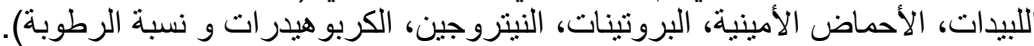

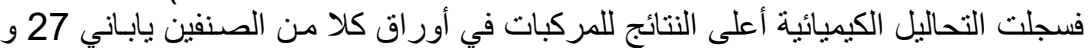

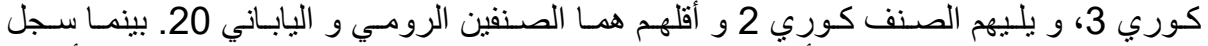

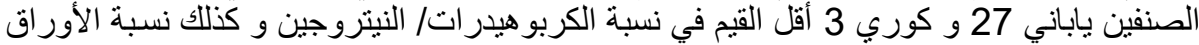

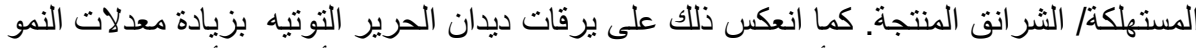

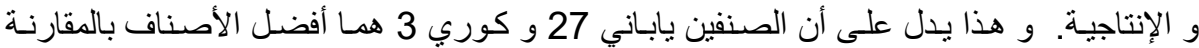

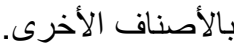

و بذلك بتضح أن معدلات القباسـات البيولوجية و الاقتصادية لديدان الحرير ترنبط بزيادة

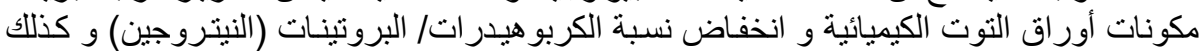

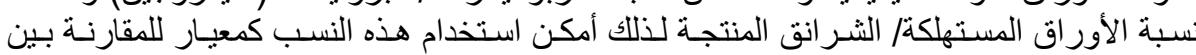

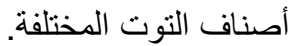

